Marina Braun-Unkhoff, Nils Hansen, Maximilian Dietrich, Torsten Methling, Kai Moshammer, Bing Yang

Entanglement of n-Heptane and iso-Butanol Chemistries in Flames Fueled by their Mixtures

Proc. Combust. Inst. 38 (2021) 2387-2395

The original publication is available at www.elsevier.com

https://dx.doi.org/10.1016/j.proci.2020.06.103

(C) $<2020>$. This manuscript version is made available under the CC-BY-NC-ND

4.0 license http://creativecommons.org/licenses/by-nc-nd/4.0/ 


\title{
Entanglement of $n$-Heptane and iso-Butanol Chemistries in Flames Fueled by their Mixtures
}

\author{
M. Braun-Unkhoff, ${ }^{{ }^{*}}$ N. Hansen,${ }^{2 *}$ M. Dietrich, ${ }^{1}$ T. Methling, ${ }^{1}$ K. Moshammer, ${ }^{3}$ B. Yang ${ }^{4}$
}

${ }^{I}$ German Aerospace Center (DLR), Institute of Combustion Technology, 70569 Stuttgart, Germany

${ }^{2}$ Combustion Research Facility, Sandia National Laboratories, Livermore, CA 94551, USA ${ }^{3}$ Physikalisch-Technische Bundesanstalt, Department of Physical Chemistry, Bundesallee 100, 38116 Braunschweig, Germany

${ }^{4}$ Center for Combustion Energy and Department of Energy and Power Engineering, Tsinghua University, Beijing, 100084, China

submitted to:

Proceedings of the Combustion Institute

$38^{\text {th }}$ Combustion Symposium 2020

"Laminar Flames Colloquium"

$\begin{array}{lr}\text { Word Count: } & \\ \text { Abstract } & 208 \\ \text { Introduction } & 535 \\ \text { Experimental Procedures } & 562 \\ \text { Model Development } & 439 \\ \text { Results and Discussion } & 1856 \\ \text { Conclusions } & 209 \\ \text { Acknowledgement } & 128 \\ \text { 40 References } & 734 \\ \text { 6 Figures 392+253+185+392+256+258 } & 1728 \\ \text { Total: } & \mathbf{6 1 9 1}\end{array}$

Color figures in online version only.

Supplementary Material is available.

\footnotetext{
* Corresponding authors:

email: marina.braun-unkhoff@dlr.de (MBU) and nhansen@sandia.gov (NH)
} 


\begin{abstract}
This paper concerns itself with the entanglement of the high-temperature oxidation chemistry of $n$-heptane and iso-butanol in flames fueled by their mixtures. While in many cases the chemistries of the individual fuel components do not interact in mixture flames, in this work, we revealed interactions between the individual species pools originating from $n$-heptane and iso-butanol oxidation. In a coordinated experimental and modeling effort, chemical structures of three low-pressure premixed flames fueled by different blends of $n$-heptane and iso-butanol were determined using flame-sampling molecular-beam mass spectrometry with synchrotron-based single-photon ionization and chemical kinetic modeling. The chemical kinetic model, which is based on the reaction set that was used previously [Braun-Unkhoff et al., Proc. Combust. Inst., 2017, 36, 1311-1319], was now extended by an $n$-heptane sub-mechanism. The overall good performance of the model allows for an extraction of chemically relevant information that highlights the entanglement between the individual fuel-specific species pools. For example, it was shown that methyl radicals, in part from iso-butanol oxidation (i.e., from the decomposition of $\alpha$ iso-butanol radicals) can participate in $n$-heptane consumption processes through $\mathrm{H}$ abstraction reactions. Further interactions are related to the formation of the methylallyl radical and aromatics formation. The relevance of such interactions is also discussed regarding the formation of oxygenated byproducts.
\end{abstract}

\title{
Keywords:
}

heptane; iso-butanol; flame-sampling mass spectrometry; chemically detailed modeling; 


\section{Introduction}

Many studies of the chemistry in low-pressure premixed flames of hydrocarbon/oxygenate mixtures suggest that different levels of interactions exist between the different species pools of the individual fuel components. While earlier work suggests that no substantial chemical interactions exist, some interactions were recently observed between the different intermediate species pools of larger fuel molecules [1-18]. In this study, further experimental and modeling evidence for such entanglement is provided of the $n$-heptane and isobutanol chemistries in the high-temperature oxidation processes in flames fueled by their mixtures. This finding is based on an integrated experimental and modeling study of the chemical structures of premixed, laminar low-pressure flames fueled by three different blends of these two components. The reaction path analysis of the formation of selected hydrocarbons and oxygenates reveals the entanglement between the $n$-heptane and iso-butanol decomposition intermediates, for example through the methyl $\left(\mathrm{CH}_{3}\right)$ radicals originating mainly from the isobutanol component (through decomposition of the respective $\alpha$-iso-butanol radical) but impacting the consumption of $n$-heptane.

This work is a continuation of our earlier work, in which we have studied the hightemperature oxidation and pollutant formation in 1,3-butadiene/n- and iso-butanol mixture flames $[1,3]$. In this earlier work, such entanglement was not reported, most probably due to the difference in the structure of the two considered specific hydrocarbon molecules. Heptane is a long-chained alkane, without any unsaturated bonds, whereas butadiene is a $\mathrm{C}_{4}$ alkene, with a conjugated double bond. Thus, their decomposition pathways will differ. The focus of similar earlier studies $[4-7,14,16]$ concerning mixture flames has been on the potential of the oxygenated component to reduce the formation of commonly known soot precursors and on the 
observed levels of oxygenated, toxic byproducts of incomplete combustion processes. It was found that the concentration of the aromatic precursors and the oxygenated byproducts scaled linearly with the percentages of the hydrocarbon and oxygenated species in fuel mixtures.

While also providing new knowledge in the form of experimentally determined, isomerresolved species mole fraction profiles and a new chemically detailed mechanism, the focus of the present paper is on the entanglement of the combustion chemistries of the prototypical hydrocarbon and oxygenated fuels $n$-heptane $\left(\mathrm{C}_{7} \mathrm{H}_{16}\right)$ and iso-butanol (iso- $\left.\mathrm{C}_{4} \mathrm{H}_{9} \mathrm{OH}\right)$, which have been studied in laminar premixed flames before as single-component fuels [19-22]. Both, $n$-heptane and iso-butanol are interesting fuel choices: $n$-Heptane is a prototypical long and straight-chain saturated hydrocarbon $\left[\mathrm{CH}_{3}-\left(\mathrm{CH}_{2}\right)_{5}-\mathrm{CH}_{3}\right]$, which is a major component in primary reference fuels for gasoline, while iso-butanol is a branched short-chained alcohol $\left[\left(\mathrm{CH}_{3}\right)_{2} \mathrm{CHCH}_{2} \mathrm{OH}\right]$ that can be derived from biomass and is being used as an additive to gasoline. The fuel combination is relevant because of the discussion on the addition of butanol made from biomass to gasoline due to its better properties compared to ethanol. $n$-Heptane is one of the two components within the gasoline surrogate fuel, the primary reference fuel PRF90. PRF90, a binary mixture consisting of $90 \%$ iso-octane and $10 \% n$-heptane, was shown to be a suitable gasoline surrogate fuel when studying the effects of knocking and ignition [23]. isoButanol has been certified by ASTM International for use as automotive spark-ignition engine fuel (gasoline) up to a $12.5 \%$ blending rate, being besides two further butanol isomers $n$-butanol and 2-butanol; see Ref. [23] and references therein. 


\section{Experimental Procedures}

The three flames investigated here are premixed laminar low-pressure $n$-heptane/isobutanol $/ \mathrm{O}_{2} / \mathrm{Ar}$ flames with varying $n$-heptane/iso-butanol ratios. The detailed conditions are provided in the Supplementary Material. The fuel composition was varied from containing 80 vol $\% n$-heptane to 60 and 40 vol\%. The conditions of Flame 1 were chosen to be in between the other two limited cases of Flame 2 (more heptane than iso-butanol) and Flame 3 (more isobutanol than heptane). All flames were stabilized on a 6-cm diameter stainless steel McKenna burner at a reduced pressure of 40 mbar (30 Torr). Argon, in a total amount of $50 \mathrm{~mol} \%$ of the cold gases, was used as a diluent. The $\mathrm{C} / \mathrm{O}$ ratio $(\mathrm{C} / \mathrm{O}=0.4)$ and the cold gas velocity $\left(65.1 \mathrm{~cm} \mathrm{~s}^{-1}\right)$ were kept identical for all the three flames. All gas flows were controlled using calibrated flow-controllers and the liquid flows were metered using two high-precision syringe pumps. The liquids were vaporized and quantitatively added into the gas stream.

The experimental work was performed using the flame-sampling molecular-beam mass spectrometer at the Advanced Light Source of the Lawrence Berkeley National Laboratory. Details have been described elsewhere [24-26] and therefore only a short description is provided here. Gases were sampled from the three burner-stabilized low-pressure flames through an opening of $\sim 400 \mu \mathrm{m}$ in a quartz sampling nozzle (opening angle $\sim 35^{\circ}$ ) into the high vacuum of a custom-built mass spectrometer. Molecules are ionized using the synchrotron-generated vacuumultraviolet radiation in a single-photon process and the respective ions are mass selected using a reflectron time-of-flight mass spectrometer. With a resolution of $m / \Delta m \sim 4000$ oxygenated and hydrocarbon species can be separated in the desired mass range, which is an essential feature for studying hydrocarbon/oxygenated mixture flames. 
Burner-probe distances were varied between 0 and $30 \mathrm{~mm}$ using a high-precision computer-controlled stepper motor to allow for sampling from various positions from within the flames. The respective spatially resolved mass spectra were recorded using well-established photon energies between 8 and $17 \mathrm{eV}$ to minimize fragmentation and to allow for isomerresolved quantification. A photoionization efficiency curve was recorded to help with the identification of the sampled intermediates not just by the mass-to-charge ratio but also by the isomer-specific ionization energies. The procedures for converting the mass spectra into quantitative isomer-specific mole fraction profiles have been described in the literature [27, 28].

About 70 flame components were quantified for each flame and their mole fraction profiles are provided in the Supplementary Material. A detailed discussion about the uncertainties is provided in Ref. [25]. In short, profiles shown here have an uncertainty in the order of about a factor of 2. Main species profiles are typically determined more accurately, i.e. within $20 \%$. However, the relative error between the individual species' mole fraction profiles from the three different flames is much smaller because the three flames were analyzed using the same experimental set-up and data reduction procedure.

Temperature profiles of the unperturbed flames were measured using OH LIF as described in Ref. [29] and are provided in the Supplementary Material. The uncertainty is expected to be $\pm 150 \mathrm{~K}$ in the post-flame zone. For the model calculations, the unperturbed temperature has been corrected to account for the probe perturbations in the preheat and flame zones. Despite the probe perturbations [30], it has been shown that such an approach leads to model predictions that are comparable with the experimental results [20, 31, 32].

\section{Model Development}


The reaction mechanism is based on the DLR reaction mechanism recently used to model the oxidation of mixtures of 1,3-butadiene/iso-butanol [1] and of 1,3-butadiene/n-butanol [3]. To this one, an $n$-heptane oxidation sub-mechanism was implemented. However, in view of existing $n$-heptane models reported in the literature, the development of a newly constructed heptane oxidation sub-mechanism was outside the focus of the present work. Instead, the public domain available CRECK model from the POLIMI group [27] was exploited here as the $n$-heptane base mechanism; this base mechanism was then adopted and coupled with the DLR mechanism by considering only the initial fuel oxidation reaction network. In total, 42 species and 1297 reactions, 1212 of them being irreversible have been incorporated. The full kinetic mechanism and the associated thermodynamic and transport data are available in the Supplementary Material (SM).

The $n$-heptane sub-mechanism considers the depletion of $n$-heptane by thermal decomposition leading directly to smaller alkyl radicals as well as by $\mathrm{H}$-atom abstraction reactions via various radicals, mainly $\mathrm{H}, \mathrm{O}, \mathrm{OH}, \mathrm{HO}_{2}$ and smaller hydrocarbon radicals, e.g. $\mathrm{CH}_{3}, \mathrm{CH}_{3} \mathrm{O}$, producing $n-\mathrm{C}_{7} \mathrm{H}_{15}$ radicals. These initiation reactions were determined by following the RGM method as described by Ref. [33]. The sub-mechanism also includes decomposition of alkyl radicals, such as $\mathrm{C}_{7} \mathrm{H}_{15}$ and $\mathrm{C}_{7} \mathrm{H}_{13}$, formed mostly by $\mathrm{H}$-abstraction of the respective fuel molecule, to various olefins, mostly smaller ones, e.g. $\mathrm{C}_{3} \mathrm{H}_{6}, \mathrm{C}_{4} \mathrm{H}_{6}, \mathrm{C}_{4} \mathrm{H}_{8}, \mathrm{C}_{5} \mathrm{H}_{8}$, and $n-\mathrm{C}_{5} \mathrm{H}_{10}$, mainly via $\beta$-scission of the first fuel radical. Reactions coefficients for these alkyl radical decomposition reactions were taken from the POLIMI group [34]. The included $\mathrm{C}_{7} \mathrm{H}_{14}$ reaction network encompasses several (reversible) $\mathrm{H}$-abstraction reactions via $\mathrm{H}, \mathrm{O}, \mathrm{OH}, \mathrm{HO}_{2}, \mathrm{O}_{2}, \mathrm{CH}_{3}$, and $\mathrm{C}_{2} \mathrm{H}_{5}$, taken from the work of Seidel et al. [20]. All further rate coefficients within the $n$-heptane sub-mechanism were taken from the POLIMI group [27], without any modifications. 
Note that the well-established lumping technique was used [27] to allow for a reduction in terms of number of species, in particular of isomers, thus building more compact reaction models; see, e.g. [34-37]. This approach has been found to be sufficient for the purpose of this study, i.e. revealing the interactions of the small species pools at high temperatures.

Computer simulations of the isobaric burner-stabilized flames were performed with the open-source software Cantera [38] using the experimental temperature profiles. In addition, initial mass flow rates and composition of the reactants as well as the burner's diameter served as further input data. For the simulations, the multi-component diffusion model and thermodiffusion were considered. Mesh points were refined to achieve equal solution tolerance; the refine criteria "slope" and "curve" were chosen such that the grid was refined to about 120 mesh points.

\section{Results and Discussion}

A large data set of newly measured concentration profiles has been collected that provides insights into the combustion chemistry of these mixture flames and that can be used as validation targets for model development - a prerequisite for revealing the entanglement of the high-temperature chemistries of the individual fuel components. This chapter is organized as follows: We begin the discussion with the description of the performance of the newly constructed chemical kinetic $n$-heptane/iso-butanol mechanism for the present system. We then provide some evidence for interesting entanglement between the individual fuel chemistries. Finally, we discuss some noteworthy chemistry occurring in which some oxygenated intermediates are directly correlated to the hydrocarbon fuel and vice versa. 
(a) Overall Performance of the Chemical Mechanism

As proof for the overall good performance of the newly constructed mechanism, the predictions of the major species $\left(\mathrm{H}_{2}, \mathrm{H}_{2} \mathrm{O}, \mathrm{CO}, \mathrm{O}_{2}, \mathrm{Ar}, \mathrm{CO}_{2}\right.$, iso- $\mathrm{C}_{4} \mathrm{H}_{8} \mathrm{O}$, and $n$-heptane) profiles are shown in the Supplementary Material. An overall satisfactorily agreement is observed, i.e. experiment and model results agree within the experimental uncertainty as indicated by the error bars. Slight deviations can be seen close to the burner surface where probe perturbations are most significant [30]. Similar levels of agreement were observed for model-experiment comparison for Flames 2 and 3 (also shown in the Supplementary Material).

This generally good agreement between experimental results and model predictions is a prerequisite for the model to provide meaningful scientific insights. It is important that the model captures the fuel decompositions accurately, because then, the model allows for the identification of the entanglement between the different species pools (from the two different fuels). It is shown in Fig. 1 that $n$-heptane is predominantly consumed through $\mathrm{H}$-abstraction forming $\mathrm{C}_{7} \mathrm{H}_{15}$ fuel radicals; these decompose either to $\mathrm{C}_{4} \mathrm{H}_{9}$ and $\mathrm{C}_{3} \mathrm{H}_{7}$ radicals or into alkenes and alkyl radicals, such as $\mathrm{C}_{2} \mathrm{H}_{4}, \mathrm{C}_{3} \mathrm{H}_{6}, \mathrm{C}_{4} \mathrm{H}_{8}, \mathrm{C}_{5} \mathrm{H}_{10}$, and $\mathrm{C}_{7} \mathrm{H}_{14}$, and such as $\mathrm{C}_{5} \mathrm{H}_{11}, \mathrm{C}_{4} \mathrm{H}_{9}, \mathrm{C}_{3} \mathrm{H}_{7}, \mathrm{C}_{2} \mathrm{H}_{5}$, and $\mathrm{CH}_{3}$, respectively. In addition, $\mathrm{C}_{5} \mathrm{H}_{11}$ radicals subsequently decompose further to form the stable species $\mathrm{C}_{2} \mathrm{H}_{4}, \mathrm{C}_{3} \mathrm{H}_{6}$, and $\mathrm{C}_{4} \mathrm{H}_{8}$ as well as the radicals $\mathrm{CH}_{3}, \mathrm{C}_{2} \mathrm{H}_{5}$, and $\mathrm{C}_{3} \mathrm{H}_{7}$. Similarly, $\mathrm{C}_{4} \mathrm{H}_{9}$ decomposes further to form $\mathrm{CH}_{3}$ and $\mathrm{C}_{3} \mathrm{H}_{6}$ or $\mathrm{C}_{2} \mathrm{H}_{4}$ and $\mathrm{C}_{2} \mathrm{H}_{5}$. Due to the lumping approach a single fuel alkyl radical is incorporated instead of the detailed fuel radical isomers network. This simplification is compensated by the appropriate formulation of the single fuel alkyl radical depletion into the different alkyl and alkene species, as described above. The detection technique used in the present work does not allow for distinguishing between the specific fuel radicals; similarly, no experimentally measured or confirmed calculated rate coefficients for the numerous 
reactions that would form the different fuel radicals network are available, with possible random and inapplicable interplays within the flame chemistry.
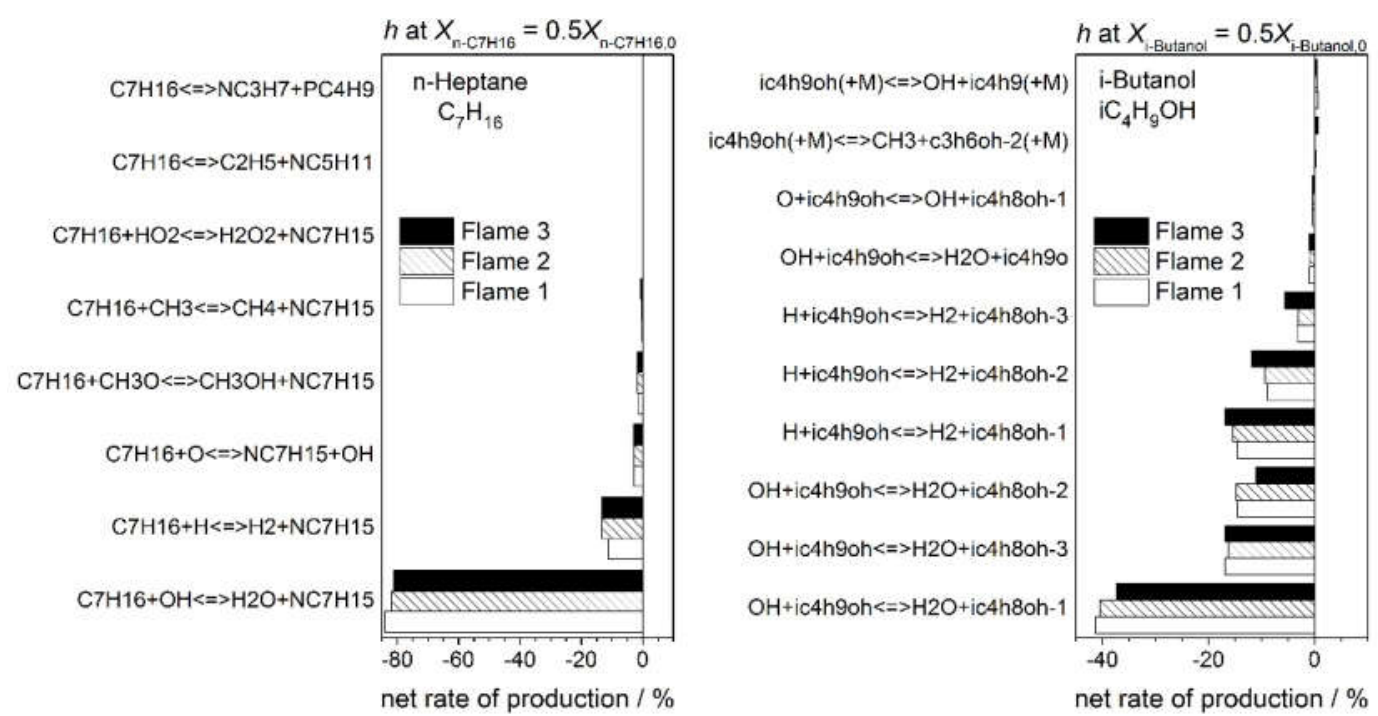

Figure 1: Rate of production analysis for $n$-heptane (left) and iso-butanol (right) in Flames 1-3.

In part caused by the branched structure, the fuel-decomposition chemistry of the isobutanol component is more diverse and $\mathrm{H}$-abstraction reactions with $\mathrm{O}, \mathrm{H}$, and $\mathrm{OH}$ from various sites are important to form various $\mathrm{C}_{4} \mathrm{H}_{9} \mathrm{O}$ fuel-radicals (Fig. 1, right). Also, due to the $\mathrm{C}-\mathrm{O}$ bond, a lumping approach would not be advisable. The formation of the iso- $\mathrm{C}_{3} \mathrm{H}_{7} \mathrm{CHOH}$ (iC4H8OH-1 in Fig. 1) is favored most probably because of the relative stability of this specific radical due to the usually low $\mathrm{C}-\mathrm{H}$ bonding dissociation energy at the $\alpha$ carbon site compared to those at other carbon sites. $\mathrm{iC} 4 \mathrm{H} 8 \mathrm{OH}-2$ and $\mathrm{iC} 4 \mathrm{H} 8 \mathrm{OH}-3$ are the other respective fuel radicals $\left(\mathrm{CH}_{3}\right)_{2} \mathrm{CCH}_{2} \mathrm{OH}$ and $\mathrm{CH}_{2}\left(\mathrm{CH}_{3}\right) \mathrm{CHCH}_{2} \mathrm{OH}$. Importantly, unimolecular dissociation reactions as discussed in Ref. [19] of iso-butanol to either form $\mathrm{CH}_{3}$, iso- $\mathrm{C}_{3} \mathrm{H}_{7}$, or iso- $\mathrm{C}_{4} \mathrm{H}_{9}$ radicals were found not to be important. The isomeric $\mathrm{C}_{4} \mathrm{H}_{9} \mathrm{O}$ radicals further decompose to form $\mathrm{CH}_{3}$ [from 
iso- $\left.\mathrm{C}_{3} \mathrm{H}_{7} \mathrm{CHOH}\right)$ ], iso- $\mathrm{C}_{4} \mathrm{H}_{8} \quad$ [iso-butene, from $\left(\mathrm{CH}_{3}\right)_{2} \mathrm{CCH}_{2} \mathrm{OH}$ ], and propene [from $\left.\mathrm{CH}_{2} \mathrm{CH}\left(\mathrm{CH}_{3}\right) \mathrm{CH}_{2} \mathrm{OH}\right]$.

The model predicts the mole fractions of the typical $\mathrm{C}_{2}$ and $\mathrm{C}_{3}$ low-pressure flame intermediates and fuel-decomposition products satisfactorily, as shown in Fig. 2 for $\mathrm{C}_{2} \mathrm{H}_{4}$ and $\mathrm{C}_{3} \mathrm{H}_{6}$ thus highlighting the model's overall performance regarding the consumption of both, $n$-heptane and iso-butanol. The flame with the highest heptane content (Flame 2) produced the largest concentration of ethylene. This trend is seen within the experimental as well as the modeling data. A chemical explanation for the observed weak correlation between $\mathrm{C}_{2} \mathrm{H}_{4}$ peak mole fraction and hydrocarbon fuel concentration is currently not available. For propene, the model predictions are within the given experimental uncertainty and the trend in concentrations is visible in the experimental data, although the model predicts very similar levels for all three flames.
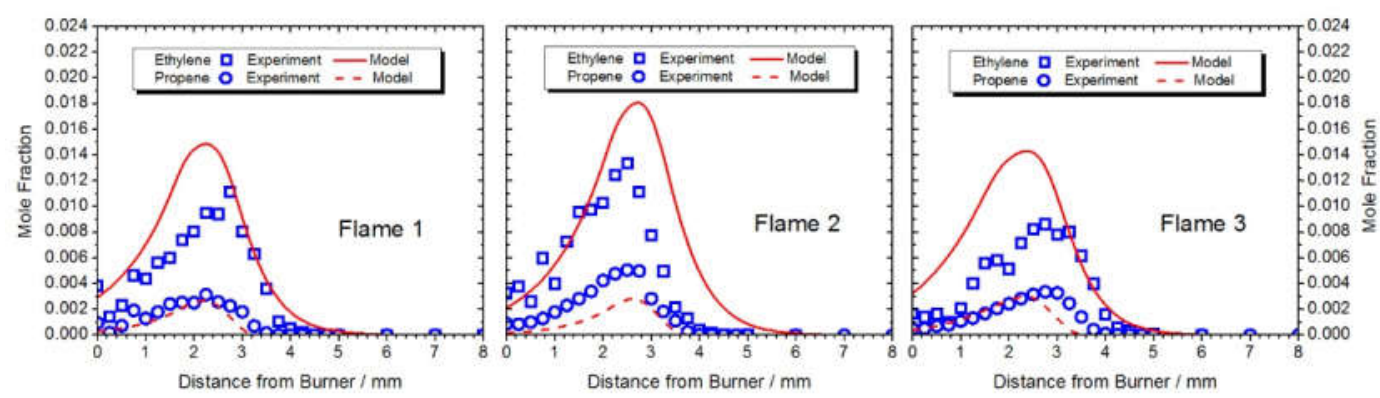

Figure 2: Experimental (symbols) and modeled (lines) mole fraction profiles of $\mathrm{C}_{2} \mathrm{H}_{4}$ and $\mathrm{C}_{3} \mathrm{H}_{6}$ for all the flames investigated here.

The newly constructed chemical detailed mechanism is also capable of favorably predicting the oxygenated species as will be discussed later. Noteworthy are the good agreements between the experimental data and the model predictions for formaldehyde, methanol, and acetaldehyde as shown below. Because no obvious fuel-structure dependent chemistry was 
identified in the reaction path analysis for formaldehyde and methanol, only acetaldehyde will be discussed in detail below.

\section{(b) Entanglement of the individual fuel's intermediate pool}

Of interest in this study is the decomposition of the $i s o-\mathrm{C}_{3} \mathrm{H}_{7} \mathrm{CHOH}$ radical which tends to form the methyl radical $\mathrm{CH}_{3}$ as a reaction product. Because the $\mathrm{CH}_{3}$ radical is being rather active in further $\mathrm{H}$-abstraction reactions (but not as reactive as $\mathrm{H}$-atoms), the $\mathrm{CH}_{3}$ formation also affects the chemistry of the second fuel-component. It is shown in the left side of Fig. 1 that Habstraction reactions by methyl radicals contribute to the consumption of $n$-heptane under the current experimental conditions. That is, $\mathrm{CH}_{3}$ mainly from iso-butanol oxidation participates in $n$-heptane oxidation processes. The additional formation of methyl radicals from iso-butanol is likely to affect the consumption of the hydrocarbon component ( $n$-heptane), leading to a slightly faster heptane consumption rate. The ROP analysis of methyl radicals performed for the three flames revealed that the $\mathrm{CH}_{3}$ formation and consumption pattern differs in two points: (i) recombination reactions with $\mathrm{CH}_{3}$ involved are more important the lower the amount of butanol; this will lead to a lower $\mathrm{CH}_{3}$ concentration; (ii) $\mathrm{CH}_{3}$ formation pathways with alcoholic compounds are becoming more relevant. However, the difference in $\mathrm{CH}_{3}$ overall concentrations for these flames is within $50 \%$ for the experimental data and about $20 \%$ for the calculated ones. The $\mathrm{CH}_{3}$ mole fraction profiles and the ROP analysis are shown in the Supplementary Material.

More opportunities to uncover entanglements between the two fuel-components stem from the different alkenes formed in the initial fuel-decomposition steps. The flame-sampled photoionization efficiency curves for $m / z=56.063\left(\mathrm{C}_{4} \mathrm{H}_{8}\right)$ is shown in Fig. 3 together with literature-known PIE curves of 1-butene and iso-butene, revealing the identity of the 
intermediates to be a mixture of these two isomers. It is worth investigating the important $\mathrm{C}_{4} \mathrm{H}_{8}$ isomers in detail.

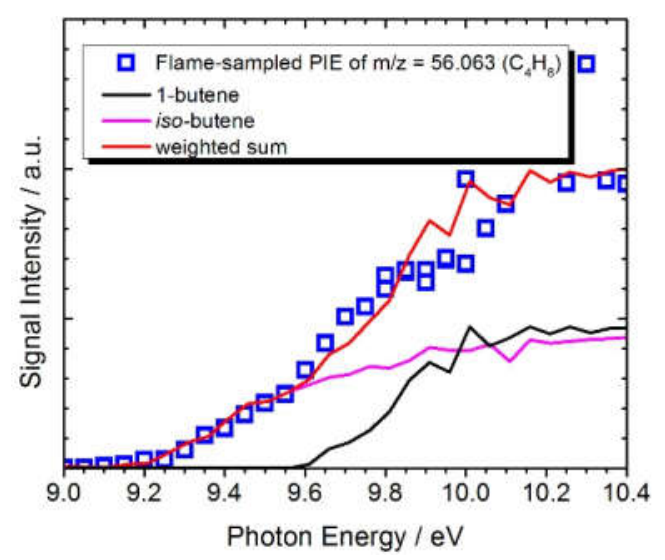

Figure 3: Flame-sampled photoionization efficiency curves for $m / z=56.063\left(\mathrm{C}_{4} \mathrm{H}_{8}\right)($ Flame 1) is compared with literature-known PIE curves of the isomeric hydrocarbons 1-butene and isobutene, which result from $n$-heptane and iso-butanol, respectively.

The rate of production analysis (Fig. 4) shows that the formation of 1-butene and isobutene can be traced back to the $n$-heptane and iso-butanol oxidation, respectively. For the 1-butene, the main formation pathway includes the $\mathrm{C}_{5} \mathrm{H}_{11}$ radical, which had been identified as a direct fuel decomposition product from $n$-heptane. Similar levels on contributions towards 1-butene stem from the oxidation of a linear $\mathrm{C}_{4} \mathrm{H}_{9}$ radical, which itself originates directly from the fuel. As expected, iso-butene is formed through direct decomposition of the $\left(\mathrm{CH}_{3}\right)_{2} \mathrm{CCH}_{2} \mathrm{OH}$ fuel radical (i-C4H8OH-2 in Fig. 4). The oxidation of the tertiary $\mathrm{C}_{4} \mathrm{H}_{9}$ radical (iC4H9T) is the second largest contributor towards iso-butene, with the radical also being formed directly from the iso-butanol fuel component. 

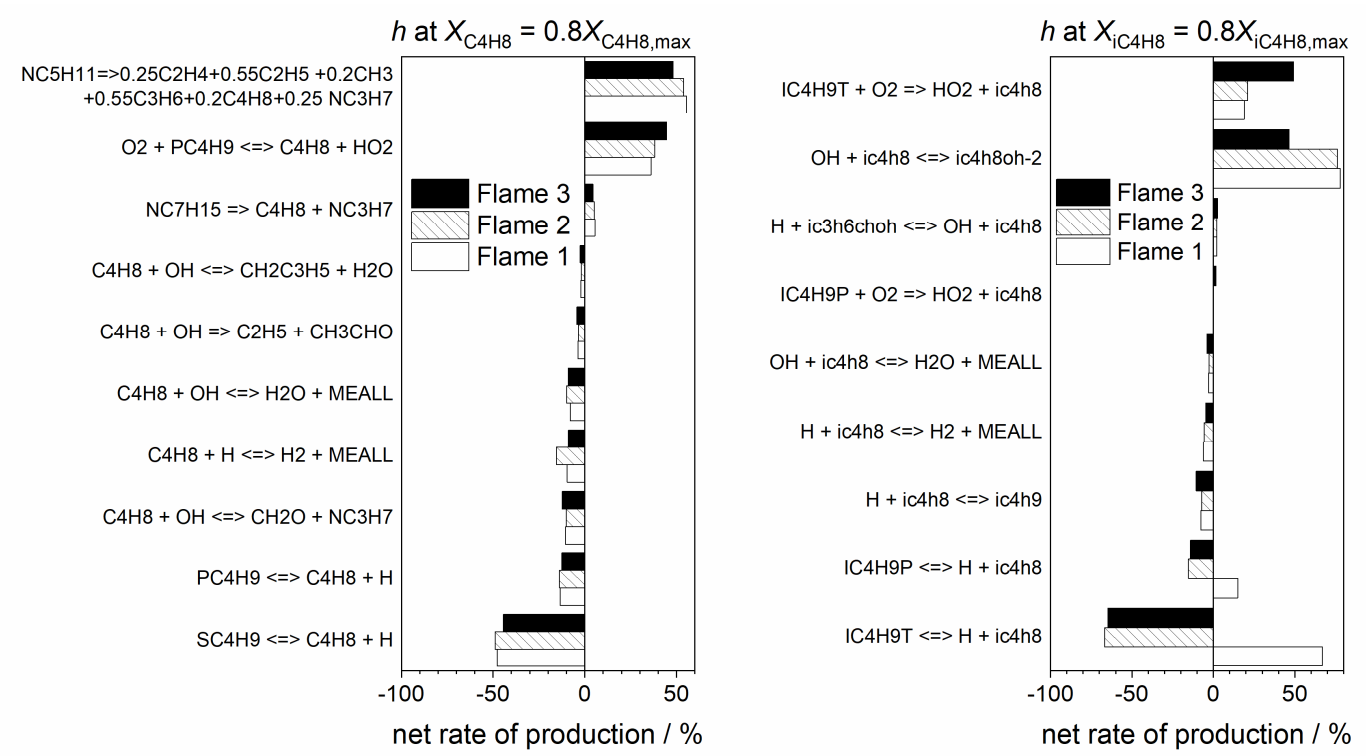

Figure 4: Rate of production analysis for 1-butene (left) and iso-butene (right) in Flames 1-3.

More interestingly than the formation of these two different intermediates directly through decomposition of the individual fuel components are their respective oxidation pathways. It can be seen from Fig. 4 that, according to the model predictions, both, the 1-butene and the iso-butene isomers are oxidized to form the methylallyl radical $\left(\mathrm{CH}_{2} \mathrm{CHCHCH}_{3}\right.$, MEALL). Thus, providing some entanglement through these connecting reactions between the oxidation chemistries of the two individual fuels. Isomerization of the iso-structure to the linear structure, which involves a transfer of a methyl group, was not found to be a viable reaction, in agreement with the findings of Huang et al. [39], who recently studied this isomerization reaction on the corresponding $\mathrm{C}_{4} \mathrm{H}_{7}$ potential energy surface. As can be seen in Fig. 5, the model's performances for the 1-butene and iso-butene are sufficient to enable a meaningful analysis of the underlying reaction pathways. 

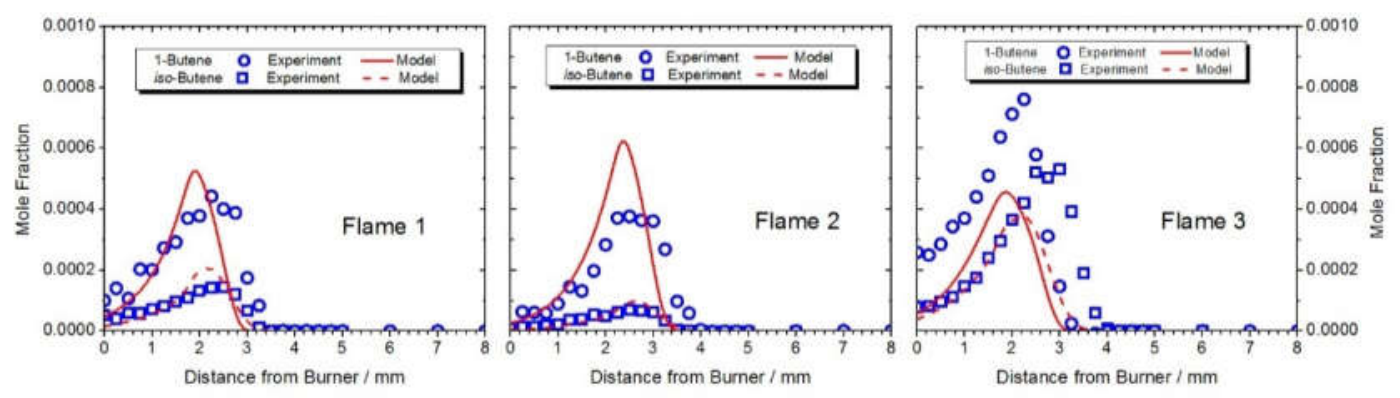

Figure 5: Experimental (symbols) and modeled (lines) mole fraction profiles of the $\mathrm{C}_{4} \mathrm{H}_{8}$ isomer iso-butene and 1-butene for all the flames investigated here.

Looking at the simulated profiles in Fig. 5, it seems that the increase of iso-butene is correlated with the increase of iso-butanol, but the variation of 1-butene is less connected to the $n-\mathrm{C}_{7} \mathrm{H}_{16}$. A reason for this only weak correlation is not entirely clear at this point.

Previous studies of similar mixture flames $[4-7,14,16]$ revealed that the formation of precursors towards benzene and other aromatic species as well as of oxygenated intermediates are correlated to the hydrocarbon or oxygenate fuel components. In contrast, the reaction path analysis in this work reveals that the aromatic precursors not necessarily need to originate from the hydrocarbon fuel component alone; similar to earlier findings of Tran et al. [16]. For example, according to our study, allene $\left(\mathrm{C}_{3} \mathrm{H}_{4}, \mathrm{CH}_{2} \mathrm{CCH}_{2}\right)$, which is predominantly produced through oxidation of $\mathrm{C}_{3} \mathrm{H}_{\mathrm{x}}(\mathrm{x} \geq 5)$ intermediates, is also formed, to a low, but noticeable extent through a direct oxidation of methacrolein $\left(\right.$ iso- $\left.\mathrm{C}_{3} \mathrm{H}_{5} \mathrm{CHO}\right)$, an intermediate in the iso-butanol oxidation. In detail, allene is formed from methacrolein via $\mathrm{H}$ abstraction, with $\mathrm{H}$ and $\mathrm{OH}$ radicals involved. The attribution of these reactions to allene formation is increasing the higher the iso-butanol amount within the specific mixture. Although most of the $\mathrm{C}_{3}$ chemistry originates from the $n$-heptane chemistry, through the methacrolein oxidation iso-butanol participates in the formation of the propargyl radical, which is commonly considered to be a precursor for benzene 
[40]. Although not shown here, Flame 2, which has the most $n$-heptane (highest hydrocarbon content) in the fuel mixture, produced the largest concentration of aromatics, while Flame 3, with the largest amount of iso-butanol, produced the smallest concentration of benzene. This effect can be traced back to a replacement effect, where the hydrocarbon component is just replaced by an alcohol that is less effective for aromatics formation. The differences in benzene concentration are quite small and only varied between 1 and $4 \times 10^{-5}$. However, the observed differences are significant because the relative uncertainty of the peak mole fraction is much smaller than the absolute uncertainty as the same data analysis procedures and calibration factors were used.

\section{(c) Formation chemistry of oxygenated intermediates}

As mentioned above, the newly constructed mechanism is also capable of predicting quite satisfactorily the oxygenated intermediates, like formaldehyde, methanol, acetaldehyde, ketene, and iso-butyraldehyde. Exemplarily we show the mole fractions of acetaldehyde for all

three flames in Fig. 6. The reaction path analysis revealed that this level of agreement was only possible when including the direct formation of acetaldehyde via the reactions of $\mathrm{C}_{7} \mathrm{H}_{14}$ with $\mathrm{OH}$ and of 1- $\mathrm{C}_{4} \mathrm{H}_{8}$ with $\mathrm{O}$, respectively forming $\mathrm{C}_{5} \mathrm{H}_{11}$ and $\mathrm{C}_{2} \mathrm{H}_{5}$ as co-products, respectively. Both, $\mathrm{C}_{7} \mathrm{H}_{14}$ and $1-\mathrm{C}_{4} \mathrm{H}_{8}$ are direct decomposition products of $n$-heptane, and the hydrocarbon component of the fuel mixtures influences directly the formation of oxygenated byproducts.

These findings are important for two reasons. First, they clearly show that even for small oxygenated fuels direct pathways to these $\mathrm{C}_{3}$ precursors $\left(\mathrm{C}_{3} \mathrm{H}_{3}\right.$ and $\left.\mathrm{C}_{3} \mathrm{H}_{5}\right)$ exist, which therefore do not necessarily need to be formed through $\mathrm{C}_{2}+\mathrm{C}_{1}$ growth reactions. For similar results, see also work by Salamanca et al. [14]. Second, large hydrocarbon fuels can participate directly in 
the formation of aldehydes.
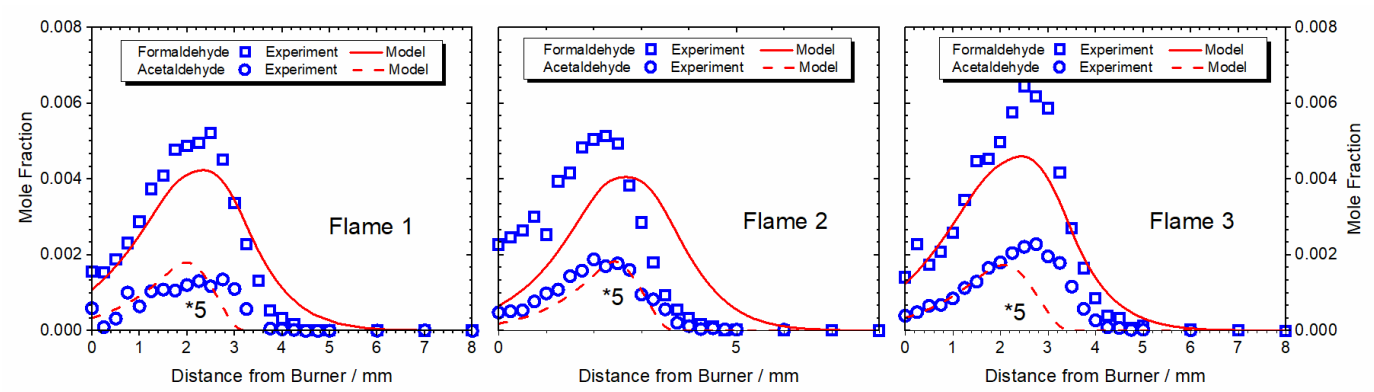

Figure 6: Experimental (symbols) and modeled (lines) mole fraction profiles of the formaldehyde $\left(\mathrm{CH}_{2} \mathrm{O}\right)$ and acetaldehyde $\left(\mathrm{CH}_{3} \mathrm{CHO}\right)$ (exp. and calculated data multiplied by 5) for all the flames investigated here.

\section{Summary and Conclusions}

Chemical structures of three low-pressure premixed flames fueled by different mixtures of $n$-heptane and iso-butanol were analyzed in a combined effort with flame-sampling molecularbeam mass spectrometry and chemically kinetic model simulations. A comprehensive set of isomer-resolved mole fraction profiles of about 70 intermediates per flame was reported in the mass range from 2 to 116 that was and can be used as targets for model validation.

The model predictions allowed to reveal several entanglements: (i) Methyl radicals, mainly from decomposition of $\alpha$ iso-butanol radicals, were shown to participate in $\mathrm{H}$-abstraction reactions from $n$-heptane; (ii) $\mathrm{C}_{3} \mathrm{H}_{4}$ intermediates were found to be formed also from the oxygenated fuel component (iso-butanol), thus playing a role in the soot precursor reaction network; (iii) According to the model, small oxygenated intermediates can be formed directly through oxidation of the decomposition products of the hydrocarbon fuel. Furthermore, the newly constructed mechanism is capable to predict most of the flame features satisfactorily. Only small trends were observed in the peak mole fractions of the $\mathrm{C}_{2}$ through $\mathrm{C}_{6}$ intermediate pool. This finding indicates that despite the largely different fuel structures similar intermediates are 
formed because both fuel molecules have sufficiently large carbon backbones allowing them to form large and small intermediates through decomposition reactions.

\section{Acknowledgements}

The measurements were performed within the "Flame Team" collaboration at the Advanced Light Source (ALS), Lawrence Berkeley National Laboratory, Berkeley, USA, and we thank the students and postdocs for the help with the data acquisition. The experiments have profited from the expert technical assistance of Paul Fugazzi. NH is supported by the U.S. Department of Energy (DOE), Office of Science, Office of Basic Energy Sciences. Sandia National Laboratories is a multimission laboratory managed and operated by National Technology and Engineering Solutions of Sandia, LLC., a wholly owned subsidiary of Honeywell International, Inc., for the U.S. Department of Energy's National Nuclear Security Administration under contract DE-NA0003525. This research used resources of the Advanced Light Source, which is a DOE Office of Science User Facility under contract no. DE-AC02-05CH11231. 


\section{References}

[1] M. Braun-Unkhoff; N. Hansen; T. Methling; K. Moshammer; B. Yang, The Influence of iso-Butanol Addition to the Chemistry of Premixed 1,3-Butadiene Flames. Proceedings of the Combustion Institute 36 (1) (2017) 1311-1319.

[2] G. Chen; W. Yu; J. Fu; J. Mo; Z. Huang; J. Yang; Z. Wang; H. Jin; F. Qi, Experimental and modeling study of the effects of adding oxygenated fuels to premixed n-heptane flames. Combustion and Flame 159 (7) (2012) 2324-2335.

[3] N. Hansen; M. Braun-Unkhoff; T. Kathrotia; A. Lucassen; B. Yang, Understanding the reaction pathways in premixed flames fueled by blends of 1,3-butadiene and n-butanol. Proceedings of the Combustion Institute 35 (2015) 771-778.

[4] K. Kohse-Höinghaus; P. Oßwald; U. Struckmeier; T. Kasper; N. Hansen; C.A. Taatjes; J. Wang; T.A. Cool; S. Gon; P.R. Westmoreland, The influence of ethanol addition on premixed fuel-rich propene-oxygen-argon flames. Proceedings of the Combustion Institute 31 (2007) 1119-1127.

[5] W.Y. Sun; B. Yang; N. Hansen; K. Moshammer, The influence of dimethoxy methane $(D M M) / d i m e t h y l$ carbonate $(D M C)$ addition on a premixed ethane/oxygen/argon flame. Proc. Combust. Inst. 36 (1) (2017) 449-457.

[6] J. Wang; U. Struckmeier; B. Yang; T.A. Cool; P. Oßwald; K. Kohse-Höinghaus; T. Kasper; N. Hansen; P.R. Westmoreland, Isomer-specific influences on the composition of reaction intermediates in dimethyl ether/propene and ethanol/propene flame. J. Phys. Chem. A 112 (39) (2008) 9255-9265.

[7] M. Zeng; J. Wullenkord; I. Graf; K. Kohse-Höinghaus, Influence of dimethyl ether and diethyl ether addition on the flame structure and pollutant formation in premixed isooctane flames. Combustion and Flame 184 (2017) 41-54.

[8] O. Korobeinichev; S. Yakimov; D. Knyazkov; T. Bolshova; A. Shmakov; J. Yang; F. Qi, A study of low-pressure premixed ethylene flame with and without ethanol using photoionization mass spectrometry and modeling. Proceedings of the Combustion Institute 33 (1) (2011) 569-576.

[9] H. Xu; C. Yao; G. Xu; Z. Wang; H. Jin, Experimental and modelling studies of the effects of methanol and ethanol addition on the laminar premixed low-pressure nheptane/toluene flames. Combustion and Flame 160 (8) (2013) 1333-1344.

[10] T. Bierkandt; T. Kasper; E. Akyildiz; A. Lucassen; P. Oßwald; M. Köhler; P. Hemberger, Flame structure of a low-pressure laminar premixed and lightly sooting acetylene flame and the effect of ethanol addition. Proceedings of the Combustion Institute 35 (1) (2015) 803-811. 
[11] V. Dias; H.M. Katshiatshia; H. Jeanmart, The influence of ethanol addition on a rich premixed benzene flame at low pressure. Combustion and Flame 161 (9) (2014) 22972304.

[12] C. Yao; X. Yang; R. Roy Raine; C. Cheng; Z. Tian; Y. Li, The effects of MTBE/ethanol additives on toxic species concentration in gasoline flame. Energy \& Fuels 23 (7) (2009) 3543-3548.

[13] L. Zhao; W. Sun; J. Yang; B. Yang, Revealing the deping effects of C2H6O isomers on a benzene flame: An experimental and modeling study. Combustion and Flame 197 (2018) 355-368.

[14] M. Salamanca; J. Wullenkord; I. Graf; S. Schmitt; L. Ruwe; K. Kohse-Höinghaus, An experimental laminar flame investigation of dual-fuel mixtures of C4 methyl esters with C2-C4 hydrocarbon base fuels. Proc. Combust. Inst. 37 (2) (2019) 1725-1732.

[15] M.D. Sylla; N. Lamoureux; L. Gasnot, Impact of methyl butanoate oxidation on NO formation in laminar low pressure flames. Fuel 207 (2017) 801-813.

[16] L.S. Tran; J. Pieper; M.R. Zeng; Y.Y. Li; X.Y. Zhang; W. Li; I. Graf; F. Qi; K. KohseHoinghaus, Influence of the biofuel isomers diethyl ether and n-butanol on flame structure and pollutant formation in premixed n-butane flames. Combustion and Flame 175 (2017) 47-59.

[17] A.M. Dmitriev; D.A. Knyazkov; T.A. Bolshova; A.G. Shmakov; O.P. Korobeinichev, The effect of methyl pentanoate addition on the structure of premixed fuel-rich $n$ heptane/toluene flame at atmospheric pressure. Combustion and Flame 162 (5) (2015) 1964-1975.

[18] R. Tripathi; U. Burke; A.K. Ramalingam; C. Lee; A.C. Davis; L.M. Cai; H. Selim; R.X. Fernandes; K.A. Heufer; S.M. Sarathy; H. Pitsch, Oxidation of 2-methylfuran and 2methylfuran/n-heptane blends: An experimental and modeling study. Combustion and Flame 196 (2018) 54-70.

[19] N. Hansen; S.S. Merchant; M.R. Harper; W.H. Green, The predictive capability of an automatically generated combustion chemistry mechanism: Chemical structures of premixed iso-butanol flames. Combustion and Flame 160 (11) (2013) 2343-2351.

[20] L. Seidel; K. Moshammer; X.X. Wang; T. Zeuch; K. Kohse-Höinghaus; F. Mauss, Comprehensive kinetic modeling and experimental study of a fuel-rich, premixed nheptane flame. Combustion and Flame 162 (5) (2015) 2045-2058.

[21] P. Oßwald; H. Güldenberg; K. Kohse-Höinghaus; B. Yang; T. Yuan; F. Qi, Combustion of butanol isomers - A detailed molecular beam mass spectrometry investigation of their flame chemistry. Combustion and Flame 158 (1) (2011) 2-15. 
[22] B. Yang; P. Oßwald; Y. Li; J. Wang; L. Wei; Z. Tian; F. Qi; K. Kohse-Höinghaus, Identification of combustion intermediates in isomeric fuel-rich premixed butanol-oxygen flames at low pressure. Combustion and Flame 148 (4) (2007) 198-209.

[23] S. Richter; M. Braun-Unkhoff; J. Herzler; T. Methling; C. Naumann; U. Riedel, An investigation of combustion properties of a gasoline primary reference fuel surrogate blended with butanol. Proc. ASME Turbo Expo (2019) GT2019-90911.

[24] T.A. Cool; A. McIlroy; F. Qi; P.R. Westmoreland; L. Poisson; D.S. Peterka; M. Ahmed, Photoionization mass spectrometer for studies of flame chemistry with a synchrotron light source. Review of Scientific Instruments 76 (9) (2005).

[25] F.N. Egolfopoulos; N. Hansen; Y. Ju; K. Kohse-Höinghaus; C.K. Law; F. Qi, Advances and challenges in laminar flame experiments and implications for combustion chemistry. Progress in Energy and Combustion Science 43 (2014) 36-67.

[26] N. Hansen; T.A. Cool; P.R. Westmoreland; K. Kohse-Höinghaus, Recent contributions of flame-sampling molecular-beam mass spectrometry to a fundamental understanding of combustion chemistry. Progress in Energy and Combustion Science 35 (2) (2009) 168191.

[27] P. Oßwald; U. Struckmeier; T. Kasper; K. Kohse-Höinghaus; J. Wang; T.A. Cool; N. Hansen; P.R. Westmoreland, Isomer-specific fuel destruction pathways in rich flames of methyl acetate and ethyl formate and consequences for the combustion chemistry of esters. J. Phys. Chem. A 111 (19) (2007) 4093-4101.

[28] T.A. Cool; K. Nakajima; C.A. Taatjes; A. McIlroy; P.R. Westmoreland; M.E. Law; A. Morel, Studies of a fuel-rich propane flame with photoionization mass spectrometry. Proc. Combust. Inst. 30 (2005) 1681-1688.

[29] N. Hansen; M.R. Harper; W.H. Green, High-temperature oxidation chemistry of $n$ butanol - experiments in low-pressure premixed flames and detailed kinetic modeling. Physical Chemistry Chemical Physics 13 (45) (2011) 20262-20274.

[30] N. Hansen; R.S. Tranter; K. Moshammer; J.B. Randazzo; J.P.A. Lockhart; P.G. Fugazzi; T. Tao; A. Kastengren, 2D-Imaging of Sampling-Probe Perturbations in Laminar Premixed Flames using Kr X-ray Fluorescence. Combust. Flame 181 (2017) 214-224.

[31] K. Moshammer; A. Lucassen; C. Togbe; K. Kohse-Höinghaus; N. Hansen, Formation of Oxygenated and Hydrocarbon Intermediates in Premixed Combustion of 2-Methylfuran. Zeitschrift Fur Physikalische Chemie-International Journal of Research in Physical Chemistry \& Chemical Physics 229 (4) (2015) 507-528.

[32] U. Struckmeier; P. Oßwald; T. Kasper; L. Böhling; M. Heusing; M. Köhler; A. Brockhinke; K. Kohse-Höinghaus, Sampling probe influences on temperature and species concentrations in molecular beam mass spectroscopic investigations of flat premixed low-pressure flames. Z. Phys. Chem. 223 (4-5) (2009) 503-537. 
[33] RMG - Reaction Mechanism Generator v3.3, http://rmg.sourceforge.net, 2011.

[34] M. Pelucchi; M. Bissoli; C. Cavallotti; A. Cuoci; T. Faravelli; A. Frassoldati; E. Ranzi; A. Stagni, Improved Kinetic Model of the Low-Temperature Oxidation of n-Heptane. Energy \& Fuels 28 (11) (2014) 7178-7193.

[35] T. Methling; S. Richter; T. Kathrotia; M. Braun-Unkhoff; C. Naumann; U. Riedel; Power, An Investigation of Combustion Properties of Butanol and Its Potential for Power Generation. J. Eng. Gas Turbines 140 (9) (2018) 091505.

[36] H. Huang; M. Fairweather; J. Griffiths; A. Tomlin; R. Brad, A systematic lumping approach for the reduction of comprehensive kinetic models. Proc. Combust. Inst. 30 (1) (2005) 1309-1316.

[37] E. Ranzi; A. Frassoldati; S. Granata; T. Faravelli, Wide-range kinetic modeling study of the pyrolysis, partial oxidation, and combustion of heavy n-alkanes. Ind. Eng. Chem. Res. 44 (14) (2005) 5170-5183.

[38] Cantera: An object-oriented software toolkit for chemical kinetics, thermodynamics, and transport processes, http://www.cantera.org, 2015.

[39] C. Huang; B. Yang; F. Zhang, Pressure-dependent kinetics on the C4H7 potential energy surface and its effect on combustion model predictions. Combust. Flame 181 (Supplement C) (2017) 100-109.

[40] J.A. Miller; M.J. Pilling; J. Troe, Unravelling Combustion Mechanisms through a Quantitative Understanding of Elementary Reactions. Proc. Combust. Inst. 30 (1) (2005) 43-88. 


\section{LIST OF FIGURE CAPTIONS}

Figure 1: Rate of production analysis for $n$-heptane (left) and iso-butanol (right) in Flames 1-3.

Figure 2: Experimental (symbols) and modeled (lines) mole fraction profiles of $\mathrm{C}_{2} \mathrm{H}_{4}$ and $\mathrm{C}_{3} \mathrm{H}_{6}$ for all the flames investigated here.

Figure 3: Flame-sampled photoionization efficiency curves for $m / z=56.063\left(\mathrm{C}_{4} \mathrm{H}_{8}\right)$ is compared with literature-known PIE curves of the isomeric hydrocarbons 1-butene and iso-butene, which result from $n$-heptane and iso-butanol, respectively.

Figure 4: Rate of production analysis for 1-butene (left) and iso-butene (right) in Flames 1-3.

Figure 5: Experimental (symbols) and modeled (lines) mole fraction profiles of the $\mathrm{C}_{4} \mathrm{H}_{8}$ isomer iso-butene and 1-butene for all the flames investigated here.

Figure 6: Experimental (symbols) and modeled (lines) mole fraction profiles of the formaldehyde $\left(\mathrm{CH}_{2} \mathrm{O}\right)$ and acetaldehyde $\left(\mathrm{CH}_{3} \mathrm{CHO}\right)$ (exp. and calculated data multiplied by 5) for all the flames investigated here. 